\title{
Ecological Efficiency of Restoration of Worn Technical Products
}

\author{
Namakonov Boris ${ }^{1}$, Melnikov Eduard ${ }^{2}$, Poliakova Anastasiia ${ }^{2}$ \\ ${ }^{1}$ Automobile and Highway Institute, Donetsk National Technical University, Gorlovka, Ukraine \\ ${ }^{2}$ MT-13 Department, Bauman MSTU, Moscow, Russia \\ Email address: \\ namakonov@ukr.net (N. Boris),mt13@bmstu.ru (M. Eduard), avpolyakova@list.ru (P. Anastasiia)
}

\section{To cite this article:}

Namakonov Boris, Melnikov Eduard, Poliakova Anastasiia. Ecological Efficiency of Restoration of Worn Technical Products. Journal of Chemical, Environmental and Biological Engineering. Vol. 3, No. 2, 2019, pp. 25-28. doi: 10.11648/j.jcebe.20190302.13

Received: July 31, 2019; Accepted: October 17, 2019; Published: October 31, 2019

\begin{abstract}
In the world no more than $0.1-0.5 \%$ of over $10 \%$ of complex technical products are removed from circulation (written off) annually due to the weight wear of machine parts. Financial, energy, labour, material and natural resources spent on their production are used by less than $1 \%$. General environmental pollution, obtained in the manufacture of these products, exceeds their weight by 100-150 times. To compensate the wear of used technical products during restoration, the material of not more than $1 \%$ of their weight is required. Energy, labour, financial and other costs, as well as the amount of technological work (taking into account the extraction of natural resources) are ten times less as compared with their production from primary material. Therefore, environmental pollution is also less by one or two orders of magnitude. Renovation of used products instead of manufacturing the same new ones allows: 1 . To save over $95 \%$ of energy, labour, material and nonrenewable natural resources previously spent on them. 2. To increase multiply the service life of products while maintaining their nominal parameters. 3. To reduce environmental pollution manifold. Renovative technologies do not require significant investments, since they are almost indistinguishable from traditional industrial processing methods and can be implemented on existing, often unloaded, production facilities. The renovation cost does not exceed $30 \%$ of a new product cost. This is the most effective technical, economic and ecological concept of preserving environment today, which is persistently ignored at the production and technical, national, educational, domestic and even scientific level. Utilization of used technical products, which has high environmental expectations, requires additional natural, and in the first place, energy resources, and it is accompanied by a loss of materials up to $60 \%$. Taking into account the annual write-off of more than $10 \%$ of the production of various complex technical products (cars - up to $20 \%$, disposable items - up to $100 \%$ ), mass renovation will reduce world extraction of natural non-renewable resources by over $10 \%$ and further overall environmental pollution will also be reduced. High ecological, technical and economic efficiency of renovation is so obvious and relevant, that it deserves the priority development of national and international resource-saving programs for renovation of technical products in terms of integrated development and conservation of the Earth interior.
\end{abstract}

Keywords: Machinery Wear, Write-off, Environmental Pollution, Product Renovation, Ecological Efficiency of Renovation

\section{Introduction}

The characteristic features of the modern society development are:

1) Progressing consumption of non-renewable primary natural resources;

2) Steady trend in the production of disposable products with the lowest ecological compatibility, since they have a small service life absorbing a significant amount of primary materials and energy. Complicated household appliances, some industrial products and even cars, which many producers and consumers would not like to repair at all, are approaching the category of «disposables»;

3) Ejection of used mass products that retain up to $95 \%$ of residual value, including up to $99 \%$ of materials that have already brought significant pollution to the environment. First of all, it concerns automobiles that consume up to a third of the world production of ferrous metals; agricultural, road-building equipment; 
technological equipment of industrial enterprises; transport and many other technical products;

Almost complete absence of any technical support by the manufacturer of the manufactured product during its life cycle. The manufacturing company does not even utilize its products. It offers only the replacement of a worn assembly, unit or part. In the industry up to $40 \%$ of all smelted ferrous metals and one-third of nonferrous metals and plastics are spent on spare parts. At the same time, over $80 \%$ of worn-out parts suitable for effective renovation are thrown away irretrievably or partially recycled, wherein more than half of the metal is lost. It is especially typical for automotive, agricultural and road engineering, which is repaired in small unprofessional workshops, mainly replacing worn parts. Of course, these workshops cannot provide adequate quality or productivity, but even so, their ecological efficiency is high enough and it should be encouraged by environmental taxes on «dirty» products $[1,2]$.

\section{The Main Cause of Environmental Pollution Is the Progressive Consumption of Resources}

The main reason of the coming global climate change (according to some data it has already come) is excessive consumption of non-renewable natural resources which are used by only $1.5 \ldots 2.0 \%$ [3]. Today in the world, most materials are used only once and are irretrievably lost. These are about $2 / 3$ of aluminum, 3/4 of steel and paper and even more plastics [4]. All material losses are associated not only with economic costs, but also with huge environmental pollution in the primary production of these materials. Today, over 100 tons of waste are produced per ton of products. Therefore, strict regulation of the primary material capacity of products, which determines the extraction volume of natural resources and production ecological compatibility of the product design, is necessary [5-7].

According to the International Gas Union, over $90 \%$ of the extractive energy resources, the burning of which is the main cause of air pollution, are used by stationary industrial enterprises. In industrial regions, emissions account for $98 \%$ of total atmospheric air pollution. If we consider that these enterprises consume up to $90 \%$ of the extractive natural resources, and their discharges are higher than emissions by one - two orders of magnitude, then it can be argued that over $90 \%$ of all environmental pollution comes from stationary industrial enterprises (mining, metallurgical, energy, engineering, chemical industry, etc.) [3, 8].

As can be seen, the consumption of non-renewable natural resources is the main cause of environmental pollution, which is many times greater than the localization capabilities of our planet. The main consumers of these resources are stationary industrial enterprises.

Thus, reduction of the pollution in the primary production will significantly improve the state of our habitat. For this, it is necessary to reduce multiply the material capacity and energy intensity of technical products and reduce the extraction of minerals. However, it is impossible, because in the near future, humanity will not be able to abandon primary natural resources. So-called «clean» technologies also require natural resources and solve only some local issues of ecological cleanliness of any production. Existing traditional industrial production cannot cope with this task, as it is based on the processing of primary resources and theoretically predetermines a significant amount of waste even in the socalled environmentally friendly technological version.

Utilization of waste equipment, which often has high environmental expectations, also requires additional natural resources; it is accompanied by additional pollution and loss of utilizable material up to $60 \%$. As a result of waste processing during production, pollution is reduced by no more than $50 \%$, while the planet is multiply supersaturated with them. Therefore, even the most advanced utilization does not solve the problem of environmental pollution.

\section{Environmentally Friendly Restoration of Worn Technical Products}

One of the ways to reduce environmental pollution, material capacity and energy intensity is an ecologically effective use of secondary material resources which are inevitably obtained both in the sphere of material production and in the sphere of consumption. We are talking about the transition to technological systems that use the existing industrial production infrastructure and provide the maximum resource, energy saving and nature conservation effect with minimal investment [9]. In modern conditions, this can be achieved at the expense of industrial renovation of used production facilities.

After the end of the first operational regulations of a technical product, up to $20 \%$ of parts are rejected, another $20 \%$ are suitable for further use without any repair effects, and $60 \%$ of parts can be restored to nominal parameters. Modern technologies of product renovation provide their prime cost of up to $30-50 \%$ of new ones and allow not only to maintain the nominal parameters, but also to improve them significantly $[10,11]$.

Over $90 \%$ of machine parts fail due to wear. Weight wear, as a result of which the product (for example, a car) becomes unsuitable for further efficient operation, does not exceed $0.5 \%$, and for details of the precision group, this value is less than $0.1 \%$. To compensate the wear when restoring parts of the primary material it is required $10-100$ times less as compared with a new part. Consequently, the energy intensity of product manufacturing is also reduced by a factor of 10 to 100 , consumption of primary resources of the Earth and environmental pollution is reduced by $10-100$ times [1].

Renovation of technical products is ten times less as compared with their manufacturing from primary materials using raw materials and energy resources, and in the same ratio the amount of pollution decreases (figure 1, figure 2 
[12]). For example, during complete overhaul of an automobile engine, $10 \ldots 15$ times less electric energy is consumed, and the amount of emissions is reduced by $200 . .250$ times as compared with a new one [13].

Even with the rejection of worn parts (up to 20\%) and pollution obtained from the implementation of technological renovation processes, production ecological compatibility of recoverable products is one to two orders of magnitude better than new ones, manufactured from primary resources.

Renovation of machines along with the saving of material, labour and natural resources not only ensures their nominal technical and economic indicators but also reduces significantly environmental pollution. This is the cleanest and most energy-saving production, which will largely solve the current ecological problems of the planet. Today renovative production has no environmental alternative $[14,15]$.

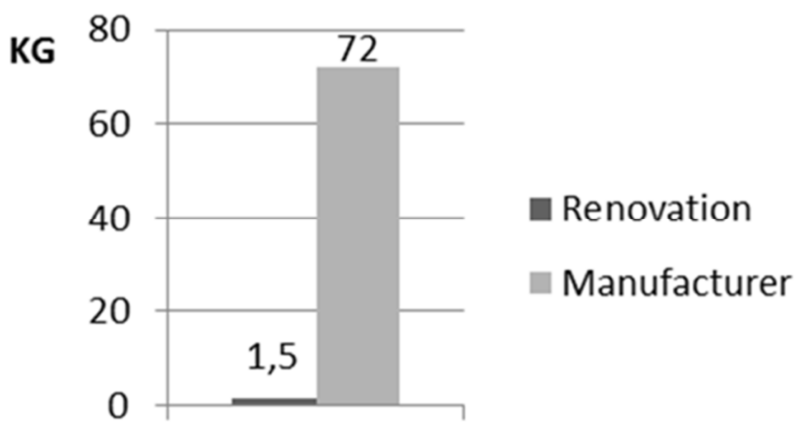

Figure 1. Metal (steel) costs for manufacturing and renovation of a part weighing $50 \mathrm{~kg}$.

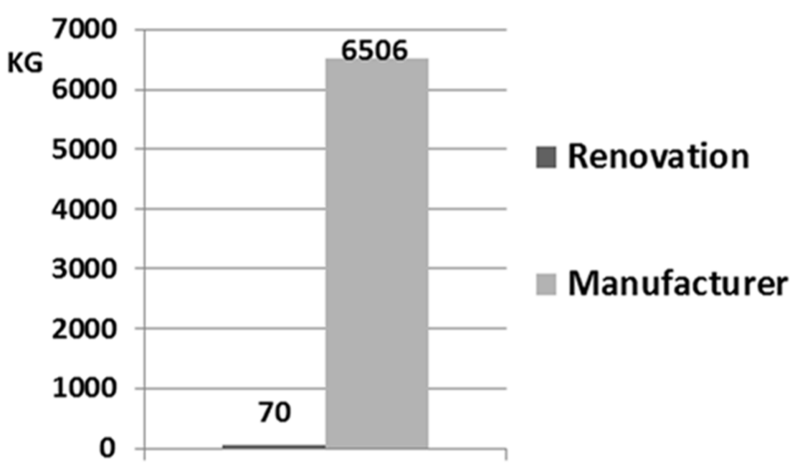

Figure 2. Nature pollution at manufacturing and renovation of a steel part weighing $50 \mathrm{~kg}$.

Modern large repair plants with high efficiency ensure operation of various equipment: railway rolling stock, sea and river vessels, planes, equipment of metallurgical, metal rolling, engineering plants, etc. This largest industry, in which up to $30 \%$ of technological equipment and labor force are involved, does not have adequate scientific, technical, organizational and economic support. Its significant ecological potential is completely ignored; therefore, its main purpose - the renovation of worn-out parts and machines - is not fully implemented.

Minimal costs are required for the implementation of renovative production because it is based on existing methods and processing techniques of machine parts. If there is a developed and underloaded industrial infrastructure and specialists of various professions, renovative production does not require any significant investment. In the country, substantial industrial facilities are not set in motion; large specialized repair plants stand idle. In current crisis economic conditions the creation of a renovative product industry is not only a cardinal solution of resource-saving and ecological problems but also the development of production, creation of new workplaces on the basis of existing unloaded enterprises without significant investments. It allows to compensate largely damage from previously collected natural resources and reduce environmental tension at minimum cost.

Serious obstacles in the development of renovative production are due to social reasons and misunderstanding of high technical, economic and environmental efficiency of renovative production by many sectors of society. Today to meet growing needs of the production, producers obtain nonrenewable natural resources (ore, coal, gas, oil, etc.) with relatively small energy and other costs. If we consider that these resources are used by only $1.5-2.0 \%$ (over $98 \%$ come to industrial waste), then their actual utility is limited by the environmental damage that they bring to the environment. However, humankind increases annual production, which leads to the progressive pollution of the biosphere.

Many consumers, producers (especially large monopolists), government officials and even quite a large number of scientists are very aggressive in advocating disposable products with subsequent utilization without any repairs and renovations. However, it is excluded even theoretically, because the life of a technical product depends on many variables and single-valued solution of the uniform strength problem for several thousand parts, for example of a car, is impossible. Therefore, even the most durable machine will have a small weight wear by the end of its regulatory cycle (up to $0.5 \%$ ) and parts of various wear rate, $60-70 \%$ of which can be restored to the nominal parameters.

«Disposable» thinking in relation to mass products, excluding its renovation, focuses producers on the intensive consumption of primary natural resources, that causes significant and irreparable damage to nature. It is explained only by monstrous egoism of Homo sapiens and the most terrible demonstration of this vice in the form of modern oligarchic capital, which is objectively predetermined by the very essence of a man as biological species. This juncture can be eliminated by tough governmental and intergovernmental regulations [16].

In modern conditions of global environmental threat, any activity must be justified first of all by environmental criteria, even to the prejudice of some consumer ones. No new, high technologies and products can be such if they do not meet environmental criteria and standards, which need to be developed and approved by law. In this aspect on the planet there is no cleaner reproduction of spent mass products than renovative production. The urgency of the problem requires its priority solution. 


\section{Conclusions}

1. At the present stage of the production development the renovation of used products to replace the production of the same new ones saves over $95 \%$ of energy, labour, material and non-renewable natural resources previously spent on them, at the same time the service life of products is increased multiply with preservation of their nominal parameters and pollution is reduced tenfold.

2. The cost of renovation is not more than $30 \%$ of a new product.

3. Taking into account the annual write-off of up to $10 \%$ of various complex technical products (and 100\% of disposable items), mass renovation will reduce global extraction of non-renewable natural resources and total environmental pollution by more than $10 \%$.

4. Renovative industrial production is an ecological breakthrough in solving the problem of preserving our environment; therefore, it deserves immediate and close attention in the state, international, scientific, industrial and technical sphere.

\section{References}

[1] Boris Namakonov. Environmental friendliness of industrial renovation of products. Monograph. Lap - Lambert Academic Publishing, ISBN: 978-3-659-16058-5, 2012, 73 p.

[2] Namakonov B. V. Ecological necessity of renovation of products. EURASIAN SCIENTIFIC FORUM, December 8, 2017 "Integration of science and education", St. Petersburg scientific center of RAS, collection of scientific articles, part 2, p. 320-328, 2018.

[3] Canilo p. M., BEIs I. S., Rivne A. I. Automobile and environment. - Kharkiv, Prapor, 2000.-303p.

[4] State of the world 2002. K. Flavin and others, translated from English, NGO "Ukraine". K., Intelsphere, 2002.-289 p.

[5] Namakonov B. V., Melnikov E. L. Technological policy of renovation as an ecological factor of sustainable development. Proceedings of the international scientific and practical forum "Russia in the XXI century: global challenges, risks and solutions", RAS, 2019 / ed. RAS M. C. H. Zalikhanov. Yeah.: June 5-6, 2019.
[6] Papiashvili A. I., Namakonov B. V. Ecological quality of renovation products; Standardization, certification, quality. No. 3, 2016, p. 59-62.

[7] Akimov T. A., Kuzmin A. P., Haskin V. V. Ecology of natureman - technique.- Yeah. - Moscow, 2001. 340 p.

[8] Namakonov B. V. Industrial renovation of products will save natural resources. Materials of the XVII scientific and practical International conference "Resource-producing, lowwaste and environmental technologies of subsoil development". Republic of Kazakhstan, Aktau, 17-20 September 2018, p. 29-32. ISBN 978-601-308-079-6.

[9] How to squeeze more out of minerals. Alan Young. Materials efficiency research group (merg), Ottawa, Canada. http://www.forest.ru/rus/org/trn/tn/45/45-8.html.

[10] Mitrokhin, N. N. Bases of production technology and repair cars: the Textbook. T. I / N. N. Mitrokhin. - Yeah.: Techpoligraftsentr, 2007. -442.

[11] Burumkulov F. H., Ivanov V. I., Velichko S. A. And others. resource Saving on the basis of increasing the turnaround time of the product. Technique in agriculture, № 5, 2008. -p. 19.

[12] Calculation of environmental pollution in the manufacture and renovation of products access mode: https://drive.google.com/file/d/1_yT0LdQsZdV27GJss6rWraiI c4gskjnR/view.

[13] Lukanin V. N., Trofimenko Yu. V. Industrial and transport ecology. - Yeah., High school, textbook for universities, 2001.$273 \mathrm{p}$.

[14] Namakonov B. V., Melnikov E. L. Ecological compatibility of renovation of technical waste products. "Innovative renovation technologies in mechanical engineering". Proceedings of the scientific and technical International conference dedicated to the 150th anniversary of the faculty of "Engineering technologies" and the Department of "technology of materials processing" MSTU. N. E. Bauman (4-5 February 2019, Moscow) - M., 2019. ISBN 978-5-70172700-5. p. 324-329.

[15] Namakonov B. V., Melnikov E. L. Ecological concept of product life cycle. "Repair, restoration, modernization", M.; Bauman Moscow state technical University, № 9, 2017, p. 21.

[16] Bolonkin A. A. Breakthrough in immortality. Mode of access: $\mathrm{http}: / /$ Bolonkin.narod.ru, http://members.nbci.com/Bolonkin/index.html). 2004. 